\title{
Medical cannabis on the NHS
}

\author{
Fiona Godlee editor in chief
}

The BMJ

Last week's recognition by the UK government that cannabis has medicinal value and should be available on prescription is an important step (doi:10.1136/bmj.k3290). It offers the hope of potentially safe and effective treatment for thousands of children and adults with conditions that are currently beyond the help of licensed drugs, and it brings the UK in line with 40 other countries and 29 US states where medicinal use of cannabis is already legal. It also greatly opens up the prospects for research.

M P Barnes is a British neurologist who has actively advocated for this change in the law. There is, he says "surprising evidence of efficacy, given the drug has been illegal in most countries for many years" (doi:10.1136/bmj.k3230). Studies have shown some evidence of benefit in chronic pain, spasticity, nausea and vomiting, and epilepsy; and there is emerging evidence in anxiety, sleep disorders, reduced appetite during chemotherapy, fibromyalgia, post-traumatic stress disorder, Parkinson's disease, agitation in dementia, bladder dysfunction, glaucoma, and Tourette's syndrome, he says. Serious side effects, including psychosis, are mainly linked to products with a high ratio of THC to CBD.

Barnes now wants rapid action to work through the many remaining obstacles to licensing and prescribing in the UK. So too does Greg de Hoedt. As a 30 year old with Crohn's disease, he has lived his entire adult life "dependent on drugs both legal and illegal" (doi:10.1136/bmj.k3287). After eight years of experimentation, he now manages his condition with a carefully designed regime of home grown vaporised and oral cannabis. "If I had waited for the UK government to enact laws that suit my needs, I would be dead," he says.

As Barnes writes, cannabis has been used as a medicine for thousands of years. The cannabis plant contains more than 100 cannabinoids and many other components. As well as deciding what constitutes a cannabis derived medicinal product, the government now needs to clarify who will be able to prescribe what, and for what conditions. More problematically, it needs to resolve how to license a plant product. Other countries have developed alternative licensing systems from which the UK can learn.

As these things are worked through, we at $T h e B M J$ will be developing information and education for doctors and their patients. We welcome research on the effects of medicinal cannabis, and we will continue to campaign for wider reform of drug policy (doi:10.1136/bmj.i6067). 